\title{
Prospects for the Development of Urban Settlements in the Digital Age
}

\author{
E. N. Zaborova* \\ Ural State University of Economics, Yekaterinburg, Russia \\ *Corresponding author.Email: ezaborova@yandex.ru
}

\begin{abstract}
Urban settlements dominate both the spatial and settlement structure of our country and the planet as a whole. The population moves to the cities due to the advantages that the city provides in terms of education, work, housing and communal conditions, leisure activities. However, in the modern conditions of the growing information and digital era, there is a significant modification of all the traditional functions of the city. In all types of activities, people increasingly tend to satisfy their needs remotely, which leads to the self-isolation of citizens in urban space, to the increasing spread of a hybrid form of employment and the atomization of society. The anthropocentric paradigm of the urban spaces, in which the living environment combines the best features of urban and rural settlements is put into practice. At the same time, the ongoing processes create prerequisites for deurbanization, relocation of citizens to other settlements. Small towns that are currently experiencing a period of decline and a decrease in population size are getting a chance for renovation.
\end{abstract}

Keywords: urbanization, cities, towns, city functions, development prospects.

\section{INTRODUCTION}

Historically, the number of cities has been growing, while their growth rate goes up with the increase in the world's population. Today, more than $55 \%$ of the world's inhabitants live in cities. Large cities are growing especially actively, turning into agglomerations and capturing more and more adjacent territories into their sphere of influence.

The modern digital age is making its own adjustments to the urbanization processes. On the one hand, conditions are being created for the emergence of "smart cities", in which, based on the introduction of digital computer technologies, prerequisites arise for an increasingly comfortable living in an urban environment, freeing a person from routine functions. On the other hand, these same communicative and technological processes act in the direction of activating the processes of deurbanization.

\subsection{Problem Statement}

What are the prospects for the development of urban settlements in the context of the unfolding digital economy? Will urban agglomerations continue to increase in size? The possibility of such a prospect was written by the Greek scientist K. Doxiadis (1914-1975), who drew attention to the giant sprawling settlements in Germany in the Ruhr area and along the Atlantic coast of the United States. He expressed the idea of an ecumenopolis - a single city for all mankind, which covers all habitable continents. A supporter of this idea was also A. Toynbee, who believed that the accelerated growth of agglomerations would lead to the formation of a world city. Official documents refer to the development of urban agglomerations as a promising strategic direction of spatial development in Russia [1]. At the same time, more and more authors are writing about the contradictions and problems that every large city encounters, that there is a natural limit to the growth of cities - people need agricultural and livestock products, they need land and water.

In our opinion, the prospects for the development of urban settlements can be assessed if we take as a basis a functional approach - an analysis of changes in the functions of cities in the modern digital era.

\section{MATERIALS AND METHODS}

Tolcott Parsons is considered to be the founder of the structural-functional approach as a research methodology, which was based on the classical concepts 
of Herbert Spencer and Emile Durkheim, Bronislaw Malinowski and Alfred Radcliffe-Brown. The structuralfunctional approach considers any phenomenon as a system consisting of interrelated elements, each of which performs its own specific function. This approach is traditionally used in scientific research, including urbanology.

Among the authors who have dealt with the problem of structuring urban space, we can name the American scientist J. Forrester, who defined the city as a complex, self-regulating system, within which stresses are created that change economic activity and cause shifts in the use of land plots, buildings and population migration, as well as domestic scientists E.G. Animitsa, N.A. Aitova, N.Y. Vlasov, A.E. Gutnov, L.A. Zelenov, V.I. Kazantsev, M.G. Svetunkov and many others. Despite the long history, there is still no consensus in the scientific literature about the functions of cities and their classification. Each of the authors offers their own classification and their own set of functions. In this article, we will use the most common and general model which distinguishes the economic, political, educational, cultural and social functions of cities.

\subsection{Empirical Base}

The work is based on the materials of empirical research conducted by the Department of Applied Sociology of the Ural State University of Economics for a number of years. Commissioned by the Federal Research Center of the Russian Academy of Sciences and the Center for Regional Sociology and Conflictology in 2019. a study was conducted on the topic "Small towns in the state policy of spatial development of Russia: social modeling of regional strategies and practices" (three focus groups with representatives of business and the public, 30 questionnaires and in-depth interviews with experts - heads of the office of the plenipotentiary, heads and deputy heads of cities, active representatives of business and the public) [2]. In 2021 - an international comparative sociological study on migration processes in the context of the COVID-19 pandemic (Czech Republic, Poland, Russia participated; internet survey, 1000 respondents in each country). We also use materials from other researchers devoted to the stated problems.

\section{RESULTS AND DISCUSSION}

\subsection{Prospects for the Development of Large Cities}

Let's analyze the changes taking place in cities based on the analysis of the modification of their functions.

The economic function of the city is very diverse, it is implemented through a whole system of economic activity and includes production, finance, transport, housing and communal services, land use, etc. Large cities (and today urban agglomerations) have always been the centers of the economic life of the country. The larger the city is, the more powerful its economic potential. Thus, "23-24\% of the total gross regional product (GRP) of the country and almost $40 \%$ of all foreign trade of Russia are concentrated in Moscow, 5\% of GRP and $10 \%$, respectively, in St. Petersburg. Moscow receives more than $40 \%$ of its budget revenues from tax revenues generated by the largest Russian companies registered in the capital" [3,pp.10-17]. More than $90 \%$ of domestic capital is also controlled by Moscow financial and industrial groups.

However, in the era of the digital economy, there is an increasing trend when the performance of the city's economic function does not require direct spatial alignment to the territory of the city, more and more types of activities are transforming to a remote format. Thus, according to the Central Bank, "over the year, the number of bank offices decreased by 5\%, or by 1.5 thousand" [4]. According to official statistics, "the number of citizens working remotely is approximately 3-3.7 million people and over the past year their number has increased more than 100 times" [5].

The trade function can be called the most important economic function of the city. Many cities were formed due to the fact that they were trade centers, they concentrated fairs, shopping malls, etc. The ancient city of Verkhoturye is an example of such a city located in the Urals, where the famous Verkhoturskaya fair took place. And today, in the 21 st century, cities are still centers of trade, attracting the population of nearby settlements to their shopping centers and shops. According to experts, Yekaterinburg ranks first or second in Russia in terms of availability of retail space, there are $440-510 \mathrm{~m} 2$ of retail space per 1000 inhabitants.

However, even in this segment of the urban economic space, the information and digital era is changing consumer behavior - citizens are making more and more purchases via the Internet, without visiting trading halls. "At the end of 2019, Russia ranked 5th among the fastest growing Internet sales markets after Mexico, India, the Philippines and China"[6]

It is known that trade does not want to lose its customers, so along with the development of online commerce, it modifies shopping centers, turning them into shopping and entertainment by creating cinemas, restaurants, cafes. Visiting a shopping center now often becomes a form of family recreation, but it is impossible not to notice the process of modifying the trading function in the city's economy.

Similar processes are taking place in other areas of the economic space of the urban environment of large cities. The transport and logistics sector and the housing and utilities sector are being actively modified. 
The political function of cities is also changing. The projects "Electronic Government", "Active Citizen" are being actively implemented, an electronic voting system is being introduced at elections, etc. All these allows citizens to get involved in the political process more actively. The development of the Internet and social networks has led to the emergence of various kinds of public communities that not only integrate their forces into networks, but also then enter the space of cities for the practical implementation of their ideas.

The most important function of cities is educational and cultural. Cities are centers of culture, education and science. It is known that the larger the city is, the more developed all its structures are and the more diverse functions it performs. Thus, there are over 1,200 scientific and technical institutions in Moscow and almost $60 \%$ of the scientific and technical potential of the whole country is concentrated here. At the same time, the digital age actively directs educational processes towards the spatially remote option of obtaining knowledge, today online education is becoming increasingly widespread. Two facts should be taken into account: online education is an irresistible trend of our time, and there are two powerful social forces that are interested in such education. These are the students themselves (getting such an education is beneficial due to the opportunity of on-the-job training at a convenient time and with less financial costs) and university leaders (due to financial benefits and image aspect).

Cities concentrate the cultural heritage of mankind, libraries, museums, cinemas, sports facilities are located here. However, today, thanks to technologies, people can join all these benefits through screen culture: almost everything is on the Internet.

The city has always been characterized by the presence of a huge number of people and the formalization of social ties, contacts between them. Today, this process has become even deeper. Information and digital processes pull a person out of the web of family and community ties, making him atomic, individual, lonely. The absence of real connections is replaced by virtual connections: $82 \%$ of Russians are registered in social networks.

The concept of a "smart city" can be called a generalizing characteristic that integrates all modern trends in the development of large cities generated by the development of information and digital processes.

The "Smart City" ideology emerged as a reaction to the entry of developed countries into the information age, to the possibility of managing a city based on information technologies, covering and linking the entire complex organizational and technical system called "smart city". The foundations for this concept appeared in the 1960s and 1970s, but its practical application began in the 1990s and coincided with the period of the spread of information and communication technologies in state and municipal administration. The main direction is the creation and implementation of new technologies that allow rational use of energy sources and minimize the impact on the environment.

"Smart city" is characterized by wireless high-speed networks, it creates conditions for the creation of socalled intelligent transport systems. A smart city makes big changes in the operation of electrical systems: it allows you to take into account both environmental requirements and solve the problem of safety and sustainability of citywide and home electrical networks. These new solutions make it possible to effectively take into account such processes as the availability of energy resources, water supply, waste disposal, combining them into a single information and digital complex. Modern information networks can monitor the operation of all systems without human intervention, they "know" the real consumption of resources at any given time and can redistribute them according to needs, increasing or decreasing the load on the designated nodal points. It is an automatic intelligent network capable of self-tuning and self-monitoring.

Innovative projects "Smart House", "Modern Yard", "Innovative Road" are being created in the urban space based on the use of big data and mathematical models. So, innovative technologies in the "Smart House" include: security system based on door/window opening sensors, motion/presence sensors in the premises; control system for water leakage and gas leakage; monitoring of energy consumption; remote control of the house using a smartphone; implementation of various scenarios (for example: night lighting mode based on motion sensors with $30 \%$ lamp brightness); access control to the room.

Projects "Modern Yard" and "Smart Street" involve creating smart lighting systems (automatic lighting modes depending on the time of day, season, etc.); video surveillance of the yard, playground and parking area; snow melting and de-icing system on pedestrian paths, roof de-icing device in places of ice formation on the roofs of buildings along pedestrian paths, as well as dispatching and control of elevator facilities, etc.

\subsection{Changing the Paradigm Approach to Intra- City Planning}

Another trend that characterizes the modern development of large cities and agglomerations can be considered the increasing introduction of an anthropocentric paradigm approach into the practice of urban planning, in which a person and his needs are placed at the center of urban development. In the middle of the twentieth century, Lewis Mumford argued that big cities "get sick", their inhabitants are in almost pathological state, because they become victims of ghosts, fears, obsessions [7, p.258]. The unnatural 
environment contributes to the growth of psychological tension, the flourishing of superstitions and other irrational ideas, social control is weakening, the number of deviations is growing. The anonymity of the big city, its freedom and depersonality, which G. Simmel wrote about, contribute to the commission of socially disapproved actions. Metropolises acquire negative vitality and become antisocial, as a result, drugs, painkillers, sleeping pills become necessary to restore mental balance. Many people have a desire to escape from the city.

The presence of a wide range of problems makes large cities an environment uncomfortable and inconvenient for residents, therefore, domestic and foreign scientists are increasingly talking about the need for sustainable (uniform, balanced) development of large cities. Scientists and practitioners are trying to smooth out the shortcomings of a large city. According to the well-known researcher Jane Jacobs, big cities can also be comfortable and convenient to live in. The main thing is for people to walk on the streets and communicate with those who live next to them. Cars, according to J. Jacobs is the main enemy of American cities and the entire Western civilization, as they very quickly destroy social activity and destroy communities. J. Jacobs does not call for changing the size of cities. She believes that it is possible to feel comfortable in a big city, because the determining factor affecting living conditions is social relations with people who are in close proximity. The problem, from her point of view, is not the size of the city, but the lack of good-neighborly relations between its residents.

The practical implementation of these ideas in modern urban planning practice can be called the experience of creating separate micro-districts within the largest cities, a kind of "rural settlements within the city", in which there is no access to transport (except for special ambulances, etc.), but there is created a large number of green spaces, small shops and cafes within walking distance, conditions for sports, recreation, social contacts, etc. Such an experience can be observed in cities such as Paris, Barcelona, etc. In this case, an attempt is made to embody the fact that every person, being atomized, still needs society, everyone needs real spatial interaction at all stages of his life.

\subsection{Prospects for the Development of Towns}

If large cities grow, turn into agglomerations and actively modify their functions, then completely different trends are observed in the development of towns. In our country, small towns account for a significant share of settlements, they traditionally perform an important function both from the point of view of the residents living in them and in terms of solving national tasks. However, the leading trend in their development is the tendency to reduce the number of residents living in towns. In small towns today, the trend of infrastructure destruction continues to increase, the reduction of skilled jobs, the curtailment of the education system, and the outflow of young people is observed. The scientific literature suggests options for the strategic development of small towns, including the transformation of small towns into tourist centers, centers for processing agricultural products and servicing the population of nearby smaller settlements, science towns, etc. [8]. One of these options can be considered the process of deurbanization - the relocation of the population from large cities to small towns.

However, it is impossible to solve the problems of towns without the participation of the state. Today, it does not have a clearly defined strategy for small towns. The inaction of the authorities actually leads to the death of towns.

\subsection{Deurbanization trends}

Information and digital technologies lead to an increase in remote forms of satisfaction of needs and an increasing spread of hybrid forms of employment. As a result of the unfolding of information and digital processes, large cities are gradually losing the spatial anchoring of their functions in the urban environment, which allows residents to move to other spaces - suburbs or small towns.

In terms of spatial aspect, we can say that the coronavirus pandemic and the isolation measures taken by the authorities have led to even greater isolation and atomization of citizens. People work, get acquainted, communicate, have fun virtually. For such behavior, there is no need to be in a crowded, noisy, polluted and full of problems city, so you can live remotely from big cities. As the results of our international research have shown, $66.9 \%$ of Russian respondents thought about moving to another locality for permanent residence due to a change in their professional status. It can be concluded that the information and digital age and the pandemic create prerequisites for strengthening the processes of deurbanization. "Thus, deurbanization in modern conditions covers not only and not so much downshifters in Russia, but also a fully qualified workforce - whether they are hired workers, selfemployed or entrepreneurs. At the same time, the space of the constant presence of a particular person is compressed" [9].

The digital age also creates technical prerequisites for such relocation: modern technologies allow building detached houses with all the comfortable conditions in which a city dweller lives today. It is an autonomous source of electricity, a warm cozy house with all modern amenities, eco-friendly environment, the ability to work remotely and enjoy the achievements of culture, etc. At the same time, people did not want to be torn away from 
live communication. The development of new forms of transport (unmanned vehicles, small air transport, etc.) act in the direction of solving transport problems, contribute to the processes of deurbanization.

Undoubtedly, this process cannot be fast. Large cities still remain attractive centers due to their functions, but in the modern era there are noticeable trends in their qualitative modification.

\section{CONCLUSIONS}

Thus, we can conclude about a revolutionary change in the economic, political, social and cultural functions of large cities. A smart city means turning an urban settlement into a center where information and digital technologies are concentrated and implemented in all spheres of life. Their consequence is the growth of remote forms of satisfaction of personal needs, the development of hybrid forms of work, the growth of online commerce, education, communication. The man is becoming more and more atomized. However, the man still remains a public entity and needs live contacts, therefore, in modern urban planning practice, there are facts of the construction of a "rural settlement" inside a large city. At the same time, technical prerequisites are being created for deurbanization - the movement of the population to smaller settlements, the town renovation.

\section{REFERENCES}

[1] The concept of the Federal target program "Socioeconomic development of small towns of the Russian Federation for the period 2015-2020". http://mert.tatarstan.ru/file/КОНЦЕПЦИЯ\%20ФЦ П\%20МГР.pdf.

[2] M. F. Chernysh, V. V. Markin, Spatial development of small cities and social policies and practices: monograph, M.: FNIC wounds, 2020. DOI: https://doi.org/10.19181/monogr.978-5-89697-3355.2020 .

[3] N. Zubarevich, The Country of cities: theory and practice of Russian urbanization, in the book. Incentives, paradoxes, failures. The City through the eyes of economists (collection), "Strelka Press" 2015. ISBN: 978-5-906264-50-3.

[4] Z. Oskolkova, Banks are actively closing branches throughout Russia, September 7 (2021). https://newdaynews-

ru.turbopages.org/newdaynews.ru/s/finance/73512 9.html?utm_source = ki_aktivno_zakryvayut_ofisy-e45484f152f65c4a3f71 f0592fdf1539).

[5] In Russia, the number of employees at remote work has increased more than 100 times. http://urbc.ru/1068102421-v-rossii-bolee-chem-v- 100-raz-vyroslo-chislo-sotrudnikov-na-udalennoyrabote.html?utm ..., 2021.

[6] What and how do residents of Russia buy on the Internet: analytics and statistics for 2020. https://cms-rating.ru/chto-i-kak-pokupayut-vinternete. 